\title{
DESIGUALDADE, POBREZA E AÇÕES DO ESTADO: A VISÃO DE ELITES POLÍTICAS NÃO-ESTATAIS
}

\author{
Éder Rodrigo Gimenes ${ }^{1}$, Angélica Ripari ${ }^{2}$ \\ e Ednaldo Aparecido Ribeiro ${ }^{3}$
}

\begin{abstract}
RESUMO
Estudos recentes evidenciam que as elites exercem forte influência nos processos políticos nacionais e que sua cultura política deve ser considerada como importante fator explicativo para os fenômenos políticos. Considerando que tais indivíduos apresentam um sistema de crenças e valores diferenciado da maioria dos cidadãos, este artigo tem por objetivo identificar o que pensam as elites sobre a desigualdade e sobre as ações do Estado para combater essa situação, focalizando especificamente atores políticos não estatais que atuam diretamente no processo de formulação e implementação de políticas sociais como membros de conselhos gestores e indiretamente como dirigentes de fundações privadas e associações sem fins lucrativos.
\end{abstract}

Palavras-chave: Distributivismo. Desigualdades. Pobreza. Elites.

\footnotetext{
Doutorando em Sociologia Política pela Universidade Federal de Santa Catarina, Brasil. ergimenes@uem.br

${ }^{2}$ Cientista Social da Universidade Estadual de Maringá, Brasil. angelicaripari@yahoo.com.br

${ }^{3}$ Professor Doutor da Universidade Estadual de Maringá, Brasil. ednaldorip@uol.com.br

Os autores agradecem aos avaliadores da revista pelas preciosas críticas e sugestões que contribuíram para a melhoria do presente artigo.
} 


\title{
INEQUALITY, POVERTY AND STATE ACTIONS: THE VIEW OF NON- STATE POLITICAL ELITES
}

\begin{abstract}
Recent studies show that elites exercise strong influence on national political processes and that their political culture should be considered as an important explanatory factor for political phenomena. Considering that such individuals have a different system of beliefs and values from the majority of citizens, this article aims to identify what the elites think about inequality and the State actions to fight against this situation, specifically focusing on non-state political players who work directly in the process of formulation and implementation of social policies as members of management councils and indirectly as managers of private foundations and non-profit associations.
\end{abstract}

Keywords: Distributivism. Inequalities. Poverty. Elites.

\section{INTRODUÇÃO}

$\mathrm{C}$ omo pessoas que se propõem a organizar e dirigir associações sem fins lucrativos pensam a desigualdade social brasileira? Como esses atores sociais avaliam a atuação do Estado nacional diante desse problema estrutural? Essas são as duas questões fundamentais que orientaram pesquisa cujos resultados apresentamos nesse artigo. 0 alvo dessa investigação foi a cultura política dos dirigentes de entidades com os objetivos mais diversos, mas que têm em comum, de forma direta ou indireta, uma preocupação com problemas sociais.

Como a maior parte dos estudos culturalistas toma a totalidade dos cidadãos de uma unidade populacional (país, estado, cidade) como objeto de análise, consideramos que nessa introdução algumas considerações sobre nosso recorte empírico sejam necessárias. A preocupação com essa dimensão cultural dos fenômenos políticos não é recente, tendo como marco de institucionalização o pioneiro estudo The Civic Culture, de Almond e Verba (1989), que continua sendo referência quando tratamos da chamada teoria da cultura política. Os autores defendem, em se tratando especificamente do regime em termos gerais, que o sucesso de um sistema político qualquer depende em grande medida da existência de um grau significativo de congruência entre as instituições concretas e os valores, crenças e atitudes políticas partilhadas pelos cidadãos.

Ribeiro e Bolognesi (2008) salientam que os estudos de cultura política, em virtude das críticas a The Civic Culture, sofreram um período de esquecimento. No entanto, tal situação começou a se alterar na década de 1980, quando autores como 
Putnam (1996) e Inglehart (1988), que compuseram a segunda geração de autores culturalistas, recuperaram as ideias principais da obra em destaque por meio de pesquisas empíricas de longo alcance geográfico ou histórico.

Para essa geração, em termos subjetivos é fundamental que ocorra a adesão dos indivíduos no plano normativo ao sistema político vigente. No caso das democracias essa afirmação se torna ainda mais relevante, pois essa forma de governo pressupõe a existência de uma larga margem de legitimidade para funcionar adequadamente.

Uma vez aceito o argumento que afirma a relevância dessa adesão, caberia perguntar se existe uma hierarquia de importância entre as disposições individuais favoráveis ou não entre os distintos grupos que compõem uma mesma nação. Mais especificamente, podemos formular as seguintes questões: a adesão normativa de quem importa? A adesão das elites é especialmente relevante?

Como já mencionamos anteriormente, a maior parte dos estudos recentes tem se mantido fiel à tradição estabelecida por Almond e Verba no que diz respeito à focalização de unidades populacionais, sem distinguir grupos ou subgrupos. Nesse sentido, os estudos contemporâneos têm sido realizados a partir de surveys nacionais e terminam por estabelecer um quadro da cultura política de uma sociedade como um todo. Ainda que a importância dessas investigações não possa ser questionada, nos parece plausível supor que se os valores dos cidadãos comuns são relevantes, aqueles partilhados pelas elites sejam ainda mais importantes (GIMENES, 2011).

Dahl (1997), ao discutir os fatores que favorecem o estabelecimento de regimes democráticos, afirma que seria difícil que um regime dessa natureza pudesse vir a existir sem que uma camada politicamente atuante do país em questão acreditasse nos méritos da democracia e rejeitasse fortemente as demais alternativas de caráter autoritário. Além disso, entendendo que pessoas diferentes provocam efeitos distintos em qualquer sistema político, o autor propõe como importante questão a identificação de quem alimenta quais crenças políticas.

Apesar de ressaltar que essa abordagem não implica na desconsideração dos valores difundidos entre 0 restante da população, aponta que o conjunto dos valores das camadas politicamente mais atuantes e envolvidas com as atividades políticas pode ser um importante fator nos estudos sobre poliarquias. Esses ativistas políticos, diferentemente da maioria das pessoas, teriam sistemas de crenças complexos e ricos, 0 que poderia ser explicado em grande medida pela associação entre essa sofisticação e os níveis de escolaridade e interesse em política. No que diz respeito à dimensão estritamente cognitiva da cultura política, o autor é categórico ao afirmar que é plausível supor que o conhecimento sobre os diferentes aspectos da vida política de um país qualquer seja maior entre os membros dessa elite do que entre a população geral. 
Por possuírem esse sistema supostamente mais sofisticado, os ativistas também teriam a maior probabilidade de serem guiados por suas crenças. Quanto mais rudimentares e desorganizadas são as crenças de um indivíduo, menores são as chances de que tais orientações guiem o seu comportamento, ou seja, exigindo um teste de congruência e densidade dos valores dos ativistas (DAHL, 1997).

Além desses fatores que tornam as crenças desse grupo particularmente relevantes, os ativistas desempenham também papel fundamental nos processo de criação e difusão dos elementos que compõem a cultura política de uma sociedade. Nos termos de Dahl, os valores e concepções políticas transmitidas por aquelas pessoas que ocupam posição de destaque na sociedade são mais facilmente assimilados pelos cidadãos médios, o que torna as elites importantes personagens não apenas na elaboração, mas também na difusão dos elementos que compõem a cultura política de uma nação ou grupo.

Em síntese, as elites importam e desconsiderar que elas exercem influência no processo político seria, no mínimo, ingênuo. Em consequência, os valores desta elite importam mais do que o da população em geral, pois, querendo ou não, são os seus membros que estão no comando do processo decisório e suas decisões afetam um leque grande de pessoas. Se a cultura política deve ser considerada um importante fator explicativo para os fenômenos políticos contemporâneos, os valores, crenças e atitudes daquelas pessoas que estão mais diretamente envolvidas nos processos políticos possuem uma relevância ainda maior (CODAT0 et al., 2007; GRYNSZPAN, 1996; LIMA; CHEIBUB, 1996; RIBEIR0; BOLOGNESI, 2008).

Vale salientar ainda que os ativistas políticos apresentam um sistema de crenças e valores diferente daquele da maioria das pessoas, o que implica afirmar que tais membros da elite possuem um maior conhecimento sobre a vida política que a maior parte da população em geral (DAHL, 1997; RIBEIR0; BOLOGNESI, 2008). Em outras palavras, as crenças e ideias de ativistas políticos e de elites apresentam-se como variáveis relevantes a serem consideradas, sobretudo em contextos como o nosso, no qual o sistema político ainda luta para se consolidar.

Nestes termos, acreditamos ser frutífera uma investigação que procura identificar quais as percepções e disposições subjetivas de uma certa elite não-estatal sobre a desigualdade social e sobre a atuação do Estado a respeito desse problema. Destacando a escassez de pesquisas sobre 0 assunto, Medeiros (2005) afirma que ao longo das últimas décadas foram produzidos vários trabalhos sobre a pobreza e a população vulnerável, mas pouco se sabe ainda sobre os que ocupam o extremo oposto e ressalta a importância de estudos sobre as posturas de estratos populacionais favorecidos.

Essa relevância se torna ainda maior quando o grupo investigado dirige entidades sem fins lucrativos que conduzem projetos que, em alguma medida, 
problematizam as estruturas de desigualdade. 0 crescimento (em termos numéricos e de capacidade de influência) que estas entidades vêm ganhando no cenário político e 0 desconhecimento do fundamento das ações que organizam faz destes atores um alvo de investigação relevante. Como argumenta Elisa Reis (2000), é inegável a centralidade das elites tendo em vista seu poder de decisão na formulação e implementação de políticas públicas, acrescentando que dificilmente uma política não desejável a eles será implementada.

Em termos ideais, uma investigação dessa natureza demandaria um survey nacional cujos entrevistados fossem esses dirigentes de entidades sem fins lucrativos, todavia, as dificuldades inerentes a uma coleta de dados tão extensiva impõem barreiras que devem ser contornadas. Um recurso viável para a análise desse tema é a redução geográfica em termos empíricos, o que implica em limites bastante claros quanto à possibilidade de generalização das conclusões. Assumindo essa limitação aproveitamos a disponibilidade de dados sobre o assunto para um município de médio porte do estado do Paraná para nossa investigação. Os resultados encontrados, portanto, não são extensivos a qualquer outro conjunto de dirigentes não estatais do território nacional, todavia, podem lançar luzes sobre as percepções desse grupo ainda pouco investigado pelos cientistas sociais brasileiros. Nossa expectativa é que essa experiência limitada de pesquisa possa inspirar outros estudos locais e, preferencialmente, de mais amplo alcance geográfico.

Sendo assim, os dados analisados decorrem da pesquisa intitulada "Cultura política e elites não estatais" (GIMENES; RIBEIR0, 2012). Foram considerados como população da pesquisa os dirigentes de entidades sociais legalmente constituídas como FASFIL no município de Maringá (PR) detentoras de algum título de reconhecimento concedido pelo Governo Federal, totalizando 113 indivíduos, dentre os quais foram sorteados aleatoriamente 82 dirigentes, compondo uma amostra representativa com nível de confiança de $95 \%$ e intervalo de confiança de 5\%. A tabulação e análise dos dados foram realizadas com a utilização do software PASW Statistics 18.

\section{DEMOCRACIA, DESIGUALDADE E ELITES}

Muitos autores sustentam que é inviável que haja pauperismo e desigualdade socioeconômica em grandes níveis em regimes ditos democráticos, muito embora, ainda que com 0 reconhecimento das desigualdades brasileiras, a população continue reconhecendo e aderindo à democracia (RENNÓ et al., 2011).

Em paralelo a essa viabilidade prática, autores como 0’Donnell (1999b) discordam piamente da possibilidade de convivência entre desigualdade e democracia. Para o autor, a democracia é mais que a decisão pelo governante. Assim, fundamentado em Dahl, busca meios mínimos para uma concepção democrática embasada em dois 
princípios básicos: (1) regimes com eleições livres e competitivas e (2) garantia de direitos básicos para que o regime democrático aconteça.

Para o autor, estes dois princípios simbolizam mais que simples garantias para a governabilidade, representam que institucionalmente se reconhece a autonomia de todo e qualquer cidadão para a tomada de decisões. Assim, o primordial na democracia é que esta institui um coletivo de agentes, de modo a denominar essa noção de "agency". Apenas garantir que as eleições sejam exequíveis não garante um regime democrático. Há graus de democracia que variam de acordo com o acesso aos direitos e liberdades, a participação, a transparência e responsabilidade pública, bem como com o contexto social.

Neste sentido, o nível de desigualdade social existente em uma democracia modifica a avaliação deste regime. Isto porque, primeiramente pela noção de agentes, se um sistema é desigual ao ponto que incapacita um grupo de indivíduos de terem sua própria autonomia e capacidade cognitiva de escolha, a desigualdade torna a democracia inviável. Um segundo ponto é que uma situação de discriminações e pauperismo conduz, consequentemente, à limitação de busca por direitos (O'DONNELL, 1999b).

Mesmo para os modelos mais fechados em termos de participação, a democracia depende de mínimos direitos políticos iguais que garantam uma decisão autônoma do indivíduo, ainda que tais direitos sejam indicativos de uma igualdade formal.

Há de se pensar ainda se, para esses modelos, uma desigualdade socialeconômica tão agravante quanto o cenário brasileiro não seria empecilho para sua execução. Isto porque, por mais que nem mesmo os autores clássicos, como Aristóteles, ou modernos, como Rousseau, acreditassem em uma igualdade plena, uma desigualdade plena tem efeitos negativos para a democracia.

0 ponto que relaciona a desigualdade com a baixa qualidade democrática em 0’Donnell é a relação estreita que há entre direitos sociais e direitos políticos. Esta correlação também é encontrada em Miguel (2002), que defende que a desigualdade de poder, tendo por consequência o monopólio de um grupo, torna o "poder do povo" inaplicável. Esta desigualdade de poder, acrescida por desigualdade de renda, de informação e de instrução, torna o quadro ainda mais emblemático. Nestes termos, uma desigualdade política causada pela exclusão de uma parcela da população tem uma consequência social indissociável.

Além dessas consequências desgastantes para a democracia, a bibliografia aborda ainda a relação entre apatia política e desigualdade. Kerstenetzky (2002) cita pesquisas nas quais se verifica que a população menos favorecida tende a não participar da política. Assim, a desigualdade social e econômica afasta uma parcela da população da 
vida política, assim como cria desinteresse de participação nesta parcela. Este desinteresse é causado pela incapacidade de participação, já que há falta de condição econômica para tal e distanciamentos produzidos socialmente, tendo em vista fatores como o tempo e o acesso a informação.

Este afastamento político que a desigualdade socioeconômica causa faz 0’Donnell afirmar que "los pobres son políticamente débiles" (0'DONNELL, 1999a, p. 73). 0 autor afirma que há uma capacidade esporádica de revisão desta cena na organização política. Sendo assim, por mais que possa haver a convivência de uma democracia estável e de quadros de grandes desigualdades sociais, há consequências desta convivência. Situações de desigualdade geram ações das elites de cooptação decorrente da perda de autonomia dos indivíduos, de repressão seletiva resultado da desigualdade de direitos e de isolamento político contra os grupos subalternos, consolidando um Estado com baixa qualidade democrática.

0 interesse destes autores no estudo sobre a desigualdade é reafirmar que esta é um produto de processos sociais, discordando, desta maneira, de posições que justificam a desigualdade praticamente como uma situação naturalizada ou julgando-a como inevitável. Neste sentido, as pesquisas demonstram que apesar de uma aparente preocupação demonstrada pela sociedade com relação ao problema, a forma como alguns grupos, principalmente os grupos de elite, têm avaliado a pobreza e as perspectivas que têm de revisão tem feito os autores concluírem que esperam a imutabilidade (0'DONNEL, 1999a; REIS, 2000; SCALON, 2007). Este é um dos pontos principais de preocupação destes estudos, uma vez que a mutabilidade é dependente da posição da elite, já que, tendo em vista a centralidade e o poder de influência deste grupo, dificilmente uma política pública que vise reverter as desigualdades seria exequível sem sua aprovação.

Deste modo, uma investigação da percepção da elite sobre a desigualdade se torna relevante, já que se houver uma parcela de indivíduos, detentores do poder, que busque diferenciações e acredite no "aprisionamento" da população em sua situação, assim como as conclusões de Scalon (2007) demonstram, a desigualdade continuará a se produzir.

Reis (2000) também investiga alguns argumentos dos grupos de elite que indicam uma aposta na imutabilidade. A autora propõe que a defesa por políticas públicas que proporcionem oportunidades seja uma "solução de tipo soma zero", já que assim teria uma ilusão de igualdade de acesso, sem, contudo, provocar perdas para os grupos privilegiados. Ou seja, as elites estudadas por Reis afirmavam desejar a igualdade, no entanto, as possibilidades apresentadas não promoviam grandes mobilidades sociais, pois a prioridade dos argumentos deste grupo está na garantia do status quo. 
Ao refletir sobre possibilidades de revisão para as desigualdades, Kerstenetzky (2002) afirma que uma revisão efetiva desses quadros de desigualdade deve passar por uma mudança das crenças e costumes, pois somente uma mudança institucional não consegue reverter desigualdades.

Os autores ressaltam ainda a impossibilidade da reversão da desigualdade apenas com o crescimento econômico. 0'Donnell (1999a) exemplifica diversos casos em que 0 crescimento econômico apenas agravou as desigualdades, entre eles no caso brasileiro. Isto indica que se as desigualdades não têm uma saída pelas instituições e nem pela economia, o caminho possível seria a reorganização política.

\section{PERCEPÇÕES SOBRE A POBREZA}

É a partir da afirmação da redução das desigualdades como elemento fundamental para o desenvolvimento de democracias com qualidade que se justifica a pesquisa cujos resultados passamos a expor agora. Identificar a intensidade da preocupação dessa elite não estatal com a pobreza no cenário nacional pode ser um interessante ponto de partida para nossa análise.

0 banco de dados utilizado nessa pesquisa contempla uma bateria de variáveis sobre as percepções dessa elite acerca da relevância de uma série de "questões nacionais" que podem nos ajudar nessa tarefa. No questionário que gerou essas medidas os entrevistados eram convidados a assinalar, para cada uma das questões, o grau de importância percebido em uma escala de 10 pontos, na qual o "0" equivale a "pouca importância" e "10" a "muita importância". Mais especificamente, são dez os objetos de avaliação: educação, saúde, pobreza, governabilidade, corrupção, desemprego, comportamento das elites, dependência externa, crise moral e proteção ao meio ambiente.

Como em todas as questões ocorreram concentrações consideráveis no ponto máximo da escala, podemos utilizar esse extremo para realizarmos comparações preliminares. Verificamos (Tabela 1) que a pobreza é avaliada como uma questão "muito importante" por 39\% dos entrevistados. 
Tabela 1- Importância de "questões nacionais"

\begin{tabular}{lcl}
\hline Questão & Muito importante (\%) & Média \\
\hline Educação & 76,8 & 9,29 \\
Saúde & 69,5 & 9,26 \\
Corrupção & 65,9 & 8,99 \\
Proteção ao meio ambiente & 45,1 & 8,62 \\
Pobreza & 39,0 & 8,51 \\
Desemprego & 39,0 & 8,44 \\
Crise moral & 39,0 & 8,09 \\
Governabilidade & 37,8 & 8,15 \\
Comportamento das elites & 16,0 & 6,93 \\
Dependência externa & 12,3 & 6,41 \\
\cline { 2 - 3 }
\end{tabular}

Fonte: Gimenes e Ribeiro (2012).

A tabela apresenta uma ordem decrescente em relação aos percentuais de respostas extremas, então podemos constatar que a pobreza não figura entre as questões mais preocupantes junto a esse grupo. Educação, saúde e corrupção aparecem de maneira inequívoca como principais temas relevantes, seguidos de longe pela proteção ambiental. Pobreza, desemprego, crise moral e governabilidade parecem formar um segundo bloco com percentuais bastante aproximados. Situação muito parecida emerge quando consideramos as médias de pontuações das escalas de importância (terceira coluna), cuja ordem é quase idêntica a dos percentuais de respostas "muito importante". É importante salientar que a média 8,51 não pode ser desprezada, porém em termos comparativos essa "questão nacional" aparece na quinta posição entre dez.

Procurando identificar atributos individuais que favoreceriam a preocupação com esse problema nacional, recodificamos a variável original para que a posição de extrema importância seja equivalente a 1 e todas as demais a 0 , ou seja, binarizamos a medida para sondar seus possíveis condicionantes. Incluímos algumas características demográficas (sexo, idade, escolaridade, católico, casado) e outras comportamentais e atitudinais (identificação ideológica, participação em conselhos gestores, índice de participação voluntária, índice de pós-materialismo e índice de adesão à democracia) ${ }^{4}$.

\footnotetext{
${ }^{4}$ A descrição da composição de tais variáveis é apresentada no Apêndice A.
} 
Tabela 2 - Condicionantes da preocupação com a pobreza

\begin{tabular}{lcc}
\hline Variável & B & Exp(B) \\
\hline Sexo &, 073 & 1,076 \\
Idade &, 012 & 1,012 \\
Escolaridade &, 500 & 1,649 \\
Católico & $1,425^{*}$ & 4,159 \\
Casado &,- 281 &, 755 \\
Identificação ideológica &,- 087 &, 917 \\
Participação em conselhos gestores &, 274 & 1,315 \\
Índice de participação voluntária &, 003 & 1,003 \\
Índice de pós-materialismo &, 191 & 1,210 \\
Índice de adesão à democracia &, $539^{*}$ & 1,715 \\
Constante & $-9,740^{*}$ &, 000 \\
\hline * sig. <0,05 & & \\
Modelo: sig = ,020 & & \\
Método Enter & & \\
\% geral de acerto 77,5 (Tabela de Classificação) & & \\
Fonte: Gimenes e Ribeiro (2012). & &
\end{tabular}

A Tabela 2 apresenta os resultados do modelo logístico a partir do método Enter. Podemos verificar que dentre as dez variáveis adicionadas como condicionantes da preocupação, apenas a medida de democratismo e a religião católica se mostraram relevantes. No que diz respeito à primeira, cada avanço no índice que possui amplitude de 0 a 12 eleva em $71,5 \%$ a chance de estar entre aqueles que atribuem extrema importância à pobreza como "questão nacional". 0 fato de ser católico, por sua vez, eleva em mais de $300 \%$ essa probabilidade.

Também dispomos de informações sobre as percepções dos membros dessa elite não estatal acerca das possíveis causas da pobreza. Os fatores abordados no survey se relacionam à ação individual e também a dimensões estruturais supostamente relacionadas à questão. Esses dados foram obtidos por meio da seguinte pergunta: "Dentre as razões relacionadas a seguir, em que medida o(a) sr.(a) acredita que cada uma delas é responsável pela pobreza no Brasil? 1) falta de vontade política; 2) não cumprimento das funções do Estado; 3) concentração de renda; 4) lógica inevitável do sistema capitalista; 5) monopolização das oportunidades; 6) falta de consciência social das elites; 7) falta de empenho dos pobres. Para cada uma delas os entrevistados 
deveriam escolher uma alternativa em uma escala de dez pontos na qual 1 equivale à "pouco responsável" e 10 à "muito responsável".

Podemos observar na Tabela 3 que a ordem estabelecida pelos percentuais de concentração no extremo da escala (muito responsável) é semelhante ao que existiria se levássemos em conta as médias das escalas, com a exceção da alternativa relativa à consciência social das elites. As duas primeiras causas apontadas nos remetem à dimensão estrutural do Estado e dos seus operadores, entendidos como principais responsáveis pela pobreza nacional. Na sequência aparecem fatores ligados à estrutura econômica da sociedade nacional e também à atuação das elites. Por fim, tanto considerando a concentração no extremo da escala quanto a média, vem a falta de empenho dos pobres, com 9,8\% e média de 6,16.

Tabela 3- Fatores responsáveis pela pobreza

\begin{tabular}{lll}
\hline Questão & Muito responsável (\%) & Média \\
\hline Falta de vontade política. & 41,5 & 8,02 \\
0 não cumprimento das funções sociais do Estado. & 26,8 & 7,33 \\
Concentração de renda. & 25,6 & 7,09 \\
Falta de consciência social das elites. & 20,7 & 6,71 \\
Monopolização das oportunidades por poucos. & 14,6 & 6,83 \\
A lógica inevitável do sistema capitalista. & 12,2 & 6,88 \\
Falta de empenho dos pobres. & 9,8 & 6,16 \\
\hline
\end{tabular}

Fonte: Gimenes e Ribeiro (2012).

Estes resultados demonstram uma grande expectativa da elite para a ação do Estado e a crença na reversão da pobreza a partir da atuação estatal. Considerando que um acesso universal e gratuito à educação e à saúde também está relegado, em grande nível, à ação do Estado, os dados indicam que, para a elite entrevistada, as grandes transformações necessárias à sociedade estão nas mãos do poder público. Há de se atentar ainda que os entrevistados responsabilizam mais a falta de vontade política do que o descumprimento das funções sociais do Estado pela pobreza no país, o que nos leva a inferir que, na perspectiva da elite, os quadros de pauperismo são causados em maior medida pela maneira como o Estado atua do que por uma falha estrutural em sua estrutura.

As conclusões de Rennó et al. (2011) reforçam esta análise. A pesquisa dos autores demonstra que a avaliação do governante é um fator que influência 0 apoio ao regime democrático em maior medida que a percepção da desigualdade ou a avaliação da equidade dos direitos civis. Nesta perspectiva, o fator que é percebido como mais 
prejudicial à qualidade democrática é a ação dos governantes. Na argumentativa, este dado reforça que "no Brasil o problema é com a aplicação da lei e não com a representatividade e responsividade do sistema político" (RENNÓ et al., 2011, p. 231).

Por outro lado, a importância que a elite relega à educação e à saúde remete a uma aposta institucional, uma confirmação de que as instituições já existentes não estão desempenhando seu papel em conformidade com a expectativa existente. Tal situação está, em algum grau, de acordo com as conclusões de Rennó et al. (2011), já que 0 problema que mais os intrigam é a condução de instituições já existentes. A aposta na educação e na saúde leva à expectativa de que a organização de instituições que prezem por uma igualdade de oportunidades seja substancial e "dê conta" dos problemas na sociedade.

No entanto, Kerstenetzky (2002) adverte que instituições democráticas não garantem a existência de uma sociedade igualitária e esta ausência de garantia, aliada a persistência do pauperismo e a reprodução das desigualdades, gera insegurança quanto à eficiência, estabilidade social e qualidade democrática.

Os dados ainda evidenciam que em paralelo à grande responsabilidade relegada ao Estado, a elite se abstém da problematização da pobreza. Reis (2000), ao se deparar com dados semelhantes em sua pesquisa, avalia que há uma falta de coletividade por parte das elites. Segundo a autora, tal ausência é gerada por não acreditarem que a pobreza é um problema real para a sociedade e, ainda, por crerem que o problema não os afeta diretamente, não compondo um fator de interesse. Esta análise é capaz de explicar porque dados nacionais alarmantes de pauperismo e desigualdade não representam uma preocupação latente para a elite.

Ao submetermos essas variáveis a uma análise fatorial, verificamos comunalidades que sugerem uma concentração interessante entre fatores ligados ao Estado, à estrutura e a ação individual, tal como a tabela anterior sugeriu. 
Tabela 4 - Análise fatorial dos fatores responsáveis pela pobreza

\begin{tabular}{llll}
\hline & \multicolumn{3}{l}{ Componente } \\
\cline { 2 - 4 } & 1 & 2 & 3 \\
\hline Não cumprimento funções sociais do Estado & 0,286 & 0,834 & 0,294 \\
Falta de vontade política & 0,322 & 0,877 & 0,024 \\
Falta consciência social das elites & 0,761 & 0,327 & $-0,265$ \\
Lógica do sistema capitalista & 0,727 & 0,259 & 0,284 \\
Monopolização das oportunidades por poucos & 0,917 & 0,160 & 0,101 \\
Concentração de renda & 0,725 & 0,398 & 0,114 \\
Falta de empenho dos pobres & 0,074 & 0,163 & 0,945 \\
\hline
\end{tabular}

Método de extração: Principal Component Analysis.

Método de rotação: Varimax com Normalização Kaiser.

KMO $=0.785$

Fonte: Gimenes e Ribeiro (2012).

A Tabela 4 mostra que as duas primeiras variáveis estão agrupadas no segundo componente com cargas fatoriais bastante elevadas $(0,834$ e 0,877$)$, indicando que os entrevistados que tendem a identificar a responsabilidade pela pobreza no descumprimento das funções sociais do Estado também tendem a apontar a falta de vontade política como causa do problema.

Com cargas fatoriais que vão de 0,725 a 0,917, as quatro variáveis seguintes se agrupam no componente 1 , compondo assim um conjunto que combina fatores estruturais, como a lógica capitalista, e aspectos ligados à dimensões individuais ou de grupos, como a falta de consciência social das elites.

De maneira isolada, o terceiro componente traz a variável relacionada à falta de empenho dos pobres, que além de ser a menos considerada responsável pela pobreza, também não se relaciona a nenhuma das outras possíveis "causas" na percepção dessa elite não estatal investigada.

\section{DESIGUALDADE E AÇÃO ESTATAL}

Procuramos agora analisar as percepções dessa elite a respeito de possíveis ações ou medidas que possam minimizar o problema da pobreza, mas antes é preciso evidenciar uma fragilidade da base de dados utilizada. Até agora as variáveis utilizadas foram geradas por questões que diretamente se relacionam à pobreza, mas as medidas 
relativas às possíveis ações de combate a essa situação focalizam a questão da desigualdade, que apesar de relacionada à pobreza, não pode ser tratada como equivalente. Desta forma, as análises que se seguem se referem às percepções dos entrevistados acerca de ações com potencial de redução dos níveis de desigualdade nacional e apenas indiretamente se remetem à pobreza.

Desta vez as variáveis foram geradas a partir da pergunta: "Em que medida o(a) sr.(a) entende que as seguintes iniciativas podem contribuir com a redução das desigualdades sociais no Brasil?" Para cada uma das ações ou medidas apresentadas os entrevistados assinalaram em uma escala de dez pontos o que mais se aproximava da sua forma de pensar, sendo que o ponto 1 equivalia à "pequena contribuição" e 10 à "grande contribuição".

Tabela 5 - Contribuições de ações/medidas para redução da desigualdade

\begin{tabular}{lcc}
\hline Questão & Grande contribuição (\%) & Média \\
\hline Apoiar iniciativas de entidades não lucrativas voltadas à & 45,1 & 8,49 \\
função social. & 30,5 & 8,17 \\
Tornar os serviços públicos sociais mais eficientes. & 14,6 & 7,23 \\
Ampliar os gastos públicos com programas sociais. & &
\end{tabular}

Na Tabela 5 observamos que, na visão dessa elite estatal, a maior contribuição para a redução da desigualdade seria oferecida justamente pelo apoio às iniciativas de entidades não lucrativas com finalidade social. A questão que gerou essa variável não qualifica de onde partiria tal apoio, mas é amplamente sabido que os recursos dessas organizações, na sua maioria, provêm de fundos públicos estatais, indiretamente podemos associar essa posição dos entrevistados ao desejo de maior apoio estatal às suas organizações sociais. Uma justificativa para a alta média indicada pelos respondentes a tal questão consiste na composição da amostra selecionada por Gimenes (2011), cujo grupo analisado se constitui em instituições que possuem certificados concedidos pelo Governo Federal, os quais tornam tais associações e fundações aptas a preitearem recursos para o desenvolvimento de suas atividades.

Com relação às afirmações de que tornar os serviços públicos sociais mais eficientes e de que a ampliação dos gastos públicos com problemas sociais seriam contribuições para a redução das desigualdades, os resultados indicam coerência por parte dos dirigentes de entidades sociais quanto ao contexto em que tais instituições atuam e de seu entendimento de que, apesar do serviço que prestam à sociedade, é de 
responsabilidade do Estado a proteção aos direitos sociais dos cidadãos, ainda que tais direitos só se legitimem, no cenário atual, por meio de parcerias com organizações sociais.

Focalizando mais diretamente medidas que teriam o Estado como executor, apresentamos agora as disposições dos entrevistados a respeito de um conjunto de políticas. Os membros da elite investigada foram convidados a avaliar cada uma das alternativas como viável e desejável, desejável mas não viável, viável mas não desejável e, finalmente, nem viável nem desejável. A Tabela 6 expõe as frequências de respostas em cada uma dessas alternativas para oito importantes ações estatais.

Tabela 6 - Percepções sobre políticas públicas

\begin{tabular}{|c|c|c|c|c|}
\hline & $\begin{array}{l}\text { Viável e } \\
\text { desejável }\end{array}$ & $\begin{array}{l}\text { Desejável mas } \\
\text { não viável }\end{array}$ & $\begin{array}{c}\text { Viável mas } \\
\text { não desejável }\end{array}$ & $\begin{array}{c}\text { Nem viável } \\
\text { nem desejável }\end{array}$ \\
\hline Educação básica gratuita e universal. & 89,0 & 8,6 & 2,4 & - \\
\hline $\begin{array}{l}\text { Desenvolvimento econômico combinado com } \\
\text { proteção ao meio ambiente. }\end{array}$ & 87,8 & 8,5 & 3,7 & - \\
\hline Programa de construção de casas populares. & 86,6 & 12,2 & 1,2 & - \\
\hline Aposentadoria por tempo de serviço. & 78,0 & 19,6 & 2,4 & - \\
\hline $\begin{array}{l}\text { Acesso universal e gratuito aos serviços de } \\
\text { saúde. }\end{array}$ & 76,8 & 22,0 & 1,2 & - \\
\hline $\begin{array}{l}\text { Seguro-desemprego para todos os } \\
\text { trabalhadores. }\end{array}$ & 41,5 & 31,7 & 15,8 & 11,0 \\
\hline $\begin{array}{l}\text { Cotas sociais nas universidades e nos serviços } \\
\text { públicos. }\end{array}$ & 39,0 & 6,1 & 15,9 & 39,0 \\
\hline $\begin{array}{l}\text { Cotas raciais nas universidades e nos serviços } \\
\text { públicos. }\end{array}$ & 20,7 & 11,0 & 19,5 & 48,8 \\
\hline
\end{tabular}

Fonte: Gimenes e Ribeiro (2012).

Com relação às políticas públicas, as respostas permitem identificar grande apoio à educação básica gratuita e universal, ao desenvolvimento econômico combinado com a proteção ambiental, aos programas de construção de casas populares, à aposentadoria por tempo de serviço e ao acesso universal e gratuito aos serviços de saúde. 0 entendimento de que são necessárias ações sociais efetivas nas áreas de educação, saúde e meio ambiente manifestado nesta bateria de questões reforça a importância atribuída pelos atores políticos não estatais acerca da importância de questões nacionais. Cabe destacar ainda que, mesmo considerando o percentual de indivíduos que entende ser difícil a implementação de tais políticas, os respondentes que entendem ser desejáveis ações efetivas que contribuam para a melhoria dos sistemas educacional, ambiental, habitacional, previdenciário e de saúde representam ao menos 96,3\% dos dirigentes entrevistados. Ainda em relação à política previdenciária, a concessão do seguro- 
desemprego a todos os trabalhadores foi considerada desejada em menor medida pelos atores analisados. Por fim, em se tratando de políticas de cotas em universidades e serviços públicos, a maior parte dos dirigentes de FASFIL maringaenses considerou não desejáveis as cotas sociais e raciais.

Os dados apresentados refletem escolhas das elites por ações gerais que não implicam em grandes modificações no cenário da própria elite. Apostas como o acesso à educação e à moradia reforçam uma adesão à igualdade de oportunidades sem necessidade de maiores reestruturações. São indicativos de caminhos para a redução das desigualdades que não alteram a condição de privilégios. Para Reis (2000), apostas como estas indicam uma não compreensão da interdependência social, uma vez que tais posturas da elite têm forte influência sobre as "formas concretas" tidas na sociedade.

\section{CONSIDERAÇÕES FINAIS}

0 presente artigo objetivou identificar a cultura política de atores de um segmento específico da elite não estatal maringaense, composta por dirigentes de entidades sociais, com relação às suas opiniões sobre questões relacionadas à desigualdade, pobreza e ação do Estado no combate a tais situações. Os entrevistados indicaram como questões mais relevantes em nível nacional a educação, a saúde e a corrupção, ficando a pobreza em quinto lugar. Além disso, atribuíram apenas a nona maior importância ao comportamento das elites, em bateria composta por dez questões, desconsiderando a importância da atuação de seu próprio grupo social.

Da mesma maneira, atribuíram maior responsabilidade ao Estado e aos políticos pela pobreza no país, em detrimento da concentração de renda, da falta de conscientização das elites, da monopolização de oportunidades e da concentração de renda, demonstrando, novamente, seu entendimento de menor compromisso com a melhoria das condições sociais no país. Tais motivos constituíram, inclusive, um dos fatores encontrados pela análise fatorial realizada.

Já com relação às ações que poderiam contribuir com a alteração do cenário de desigualdades, os gestores atribuíram maior contribuição às entidades como aquelas que dirigem, com menores relevâncias às ações estatais, o que permite inferir que mesmo responsabilizando o Estado pelos problemas sociais, tais indivíduos entendem em maior medida que as entidades sociais que dirigem podem atuar na redução da pobreza.

Por fim, os entrevistados demonstraram simpatia por ações sociais nas áreas de educação, saúde, habitação, previdência social e meio ambiente, mas declararam descontentamento com políticas de cotas sociais e raciais em universidades e serviços públicos, o que representaria uma manutenção da elitização de tais instituições. 
Diante do exposto, é possível inferir que a cultura política dos atores não estatais maringaenses confirma nossas expectativas teóricas iniciais, uma vez que tais indivíduos entendem que os problemas sociais relacionados à pobreza e desigualdade são de responsabilidade do Estado, eximindo as elites da culpa. No entanto, em se tratando de perspectiva de melhoria no cenário social, os dirigentes entendem que as próprias entidades são mais relevantes que o Estado em termos de ações sociais, mas se apresentam contrários a determinadas políticas públicas de inclusão. A elite política não estatal maringaense entende ainda que a responsabilização do Estado pela pobreza e desigualdade, o aumento do investimento em entidades sociais em detrimento do poder público e o desenvolvimento de políticas públicas específicas devem contribuir para a melhoria das condições sociais da população.

Tais indivíduos defendem que mantendo as instituições existentes e promovendo mudanças na atuação das pessoas diretamente envolvidas com o Estado poderiam se reverter os quadros de desigualdade. Desta forma, conforme mencionado anteriormente, a avaliação das elites contribui em maior medida para a imutabilidade da situação do que para sua alteração.

0 desejo verificado de manutenção dos quadros de desigualdade e de pouca relevância atribuída aos quadros de pauperismo denota uma cultura política que retifica as desigualdades sociais. Sendo assim, a responsabilização do Estado e a escolha por políticas públicas que não promovem grandes revisões sociais compõem elementos para 0 isolamento político de uma parcela da população em detrimento da manutenção dos privilégios já garantidos para o grupo estudado, configurando assim uma baixa qualidade democrática.

\section{REFERÊNCIAS}

ALMOND, Gabriel; VERBA, Sidney. The civic culture: political attitudes and democracy in five nations. Princeton: Princeton University Press, 1989.

CODATO, Adriano et al. (Org.). Quem governa? um estudo das elites políticas do Paraná. Curitiba: Universidade Federal do Paraná, 2007.

DAHL, Robert Alan. Poliarquia: participação e oposição. São Paulo: Universidade de São Paulo, 1997.

GIMENES, Eder Rodrigo. Cultura política e democracia: apoio difuso e específico entre um segmento da elite não estatal do município de Maringá (PR). 2011. Dissertação (Mestrado em Ciências Sociais) - Universidade Estadual de Maringá, Maringá. 2011.

GIMENES, Eder Rodrigo; RIBEIR0, Ednaldo Aparecido. Cultura política e elites não estatais. São Paulo: Consórcio de Informações Sociais, 2012. Disponível em 
$<$ http://www.nadd.prp.usp.br/cis/DetalheBancoDados.aspx?cod=B466>. Acesso em: 5 jul. 2013.

GRYNSZPAN, Mario. A teoria das elites e sua genealogia consagrada. Revista Brasileira de Informação Bibliográfica em Ciências Sociais, Rio de Janeiro, n. 41, p. 35-83, jan./jun. 1996.

INGLEHART, Ronald. The renaissance of political culture. American Political Science Review, Baltimore, v. 82, n. 4, p. 1203-1230, 1988.

KERSTENETZKY, Celia Lessa. Por que se importar com a desigualdade. Dados: Revista de Ciências Sociais, Rio de Janeiro, v. 45, n. 4, p. 649-675, 2002.

LIMA, Maria Regina Soares; CHEIBUB, Zairo Borges. Instituições e valores: as dimensões da democracia na visão da elite brasileira. Revista Brasileira de Ciências Sociais, São Paulo, n. 31, p. 83-110, 1996.

MEDEIROS, Marcelo. 0 estudo dos ricos no Brasil. Econômica, Rio de Janeiro, v. 17, n. 1, p. 99-128, jun. 2005.

MIGUEL, Luís Felipe. A democracia domesticada: bases antidemocrátricas do pensamento democrático contemporâneo. Dados: Revista de Ciências Sociais, Rio de Janeiro, v. 45, n. 3, p. 483-510, 2002.

0'DONNELL, Guillermo. Pobreza y desigualdad en América Latina: algunas reflexiones políticas. In: TOKMAN, Victor; O'DONELL, Guillermo. Pobreza y desigualdad en América Latina. Buenos Aires: Paidós, 1999a. p. 69-93.

Teoria democrática e política comparada. Dados: Revista de Ciências Sociais, Rio de Janeiro, v. 42, n. 4, p. 577-654, 1999b.

PUTNAM, Robert David. Comunidade e democracia: a experiência da Itália Moderna. Rio de Janeiro: Fundação Getúlio Vargas, 1996.

REIS, Elisa. Percepção da elite sobre pobreza e desigualdade. Revista Brasileira de Ciências Sociais, São Paulo, v. 15, n. 42, p. 143-152, fev. 2000.

RENNÓ, Lúcio et al. Legitimidade e qualidade da democracia no Brasil: uma visão da cidadania. São Paulo: Inermeios, 2011.

RIBEIRO, Ednaldo Aparecido; BOLOGNESI, Bruno. As elites paranaenses e a democracia: explorando a estrutura dimensional e os determinantes dos seus valores e atitudes políticas. Revista Tomo, São Cristóvão, n. 12, p. 83-110, jan./jun. 2008.

SCALON, Celi. Justiça como igualdade? A percepção da elite e do povo brasileiro. Revista Sociologias, Porto Alegre, ano 9, n. 18, p. 126-149, jun./dez. 2007. Disponível em: $<$ http://www.scielo.br/pdf/soc/n18/n18a07.pdf>. Acesso em: 3 ago. 2012. 


\section{APÊNDICE A - INFORMAÇÕES TÉCNICAS DAS VARIÁVEIS}

\section{Importância de questões nacionais}

1) Questão (comum): Considerando uma escala em que 1 representa "pouca importância" e 10 representa "muita importância", a seu ver, qual a importância das seguintes questões para o Brasil atualmente?

[V33] Educação.

[V34] Saúde.

[V35] Pobreza.

[V36] Governabilidade e gestão estatal.

[V37] Corrupção.

[V38] Desemprego.

[V39] Comportamento das elites.

[V40] Dependência externa.

[V41] Crise moral.

[V42] Proteção do meio ambiente.

Codificação: $\quad 1=$ Pouca importância.

$$
2=2
$$$$
3=3
$$$$
4=4
$$$$
5=5
$$$$
6=6
$$$$
7=7
$$

$8=8$

$9=9$

$10=$ Muita importância.

Recodificação: Sem necessidade.

\section{2) Preocupação com a pobreza}

Considerando uma escala em que 1 representa "pouca importância" e 10 representa "muita importância", a seu ver, qual a importância das seguintes questões para o Brasil atualmente?

[V35] Pobreza. 
Codificação: $\quad 1=$ Pouca importância.

$2=2$

$3=3$

$4=4$

$5=5$

$6=6$

$7=7$

$8=8$

$9=9$

10= Muita importância.

Recodificação: $\quad 0$ = Alguma importância.

1 = Muita importância.

3) $\operatorname{Sexo}$

[V01] Questão: Sexo.

Codificação: $\quad 1=$ Feminino.

$2=$ Masculino.

Recodificação: Sem necessidade.

4) Idade

[V02] Questão: Idade.

Codificação: Aberta.

Recodificação: $\quad$ Sem necessidade (unidade $=$ anos de vida).

\section{5) Escolaridade}

[V03] Questão: Qual o nível educacional mais alto que o(a) Sr(a) atingiu?

Codificação: $\quad 0=$ Não frequentou a escola.

$1=$ Ensino Fundamental incompleto.

$2=$ Ensino Fundamental completo.

$3=$ Ensino Médio incompleto.

4= Ensino Médio completo.

$5=$ Ensino Superior incompleto.

$6=$ Ensino Superior completo.

7 = Pós-Graduação. 
Recodificação: Sem necessidade.

\section{6) Católico} sim, qual?

[V05] Questão: O(A) Sr(a) pertence a alguma religião ou grupo religioso? Se

Codificação: $\quad$ l $\quad$ = Não pertence a nenhuma religião ou grupo religioso.

$1=$ Católico Romano.

$2=$ Protestante.

$3=$ Judeu.

$4=$ Muçulmano.

$5=$ Religiões de origem asiática.

$6=$ Espírita.

$7=$ Evangélico.

$8=$ Religiões de origem africana.

$9=$ Outra. Qual?

Recodificação: $\quad 0=$ Outras religiões.

1 = Católico Romano.

7) Casado

[V06] Questão: Atualmente, o(a) Sr(a) está:

Codificação: $\quad 1=$ Casado.

$2=$ Morando junto como casado.

$3=$ Divorciado.

$4=$ Separado.

$5=$ Viúvo.

$6=$ Solteiro.

Recodificação: $\quad 0=$ Não casado.

1 = Casado ou morando junto como casado.

\section{8) Identificação ideológica}

[V149] Questão: Hoje em dia, quando se conversa de tendências políticas, fala-se de pessoas que simpatizam mais com a esquerda e de pessoas que simpatizam mais com a direita. De acordo com o sentido político que os termos "esquerda" e "direita" têm para $0 \mathrm{sr} . / \mathrm{sra}$, onde o sr./sra. se situa nesta escala? Indique o número nessa escala que se aproxima mais da sua própria posição. 
Codificação: $\quad 1=$ Esquerda.

$$
\begin{aligned}
& 2=2 \\
& 3=3 \\
& 4=4 \\
& 5=5 \\
& 6=6 \\
& 7=7 \\
& 8=8 \\
& 9=9 \\
& 10=\text { Direita. }
\end{aligned}
$$

Recodificação: Sem necessidade.

9) Participação em conselhos gestores

[V185] Questão: O(A) sr.(a) participa de conselhos gestores?
Codificação: $\quad$ = Não participa. $1=$ Participa.

Recodificação: Sem necessidade.

\section{0) Índice de participação voluntária}

Questão (comum): Agora eu vou ler uma lista de organizações/associações voluntárias e gostaria de saber se o(a) Sr(a). participa ou não de cada uma delas.

[V166] Igreja ou organização/grupo de religião.

[V167] Organização/associação esportiva ou recreativa.

[V168] Organização/associação artística, musical ou educacional.

[V169] Sindicato.

[V170] Partido político.

[V171] Organização/associação de meio ambiente.

[V172] Associação profissional.

[V173] Organização/associação humanitária ou de caridade.

[V174] Movimentos sociais.

$\begin{array}{ll}\text { Codificação: } & 0=\text { Não participa. } \\ & 1=\text { Participa. }\end{array}$

Recodificação: Sem necessidade.

0 índice foi construído a partir da somatória das variáveis V166 a V174 e varia de 0 a 9. 


\section{Índice de materialismo e pós-materialismo}

[v17] Se tivesse que escolher, qual dessas coisas o(a) $\operatorname{Sr}(a)$. diria que é a mais importante atualmente?

[V18] E em segundo lugar?

Codificação: $\quad 1=$ Manter a ordem no País.

$2=$ Aumentar a participação do povo nas decisões importantes do Governo.

$3=$ Combater 0 aumento dos preços.

$4=$ Proteger a liberdade de expressão.

Recodificação: $\quad 1=0$

$2=1$.

$3=0$.

$4=1$.

[V19] Aqui está outra lista. Em sua opinião, qual dessas coisas é a mais importante?

[V20] E em segundo lugar?

Codificação: $\quad 1$ = Uma economia estável.

$2=$ Progresso em direção a uma sociedade mais humana e menos impessoal.

$3=$ Progresso em direção a uma sociedade na qual as idéias têm mais valor que o dinheiro.

$4=$ Combate à criminalidade.

Recodificação: $\quad 1=0$

$2=1$.

$3=1$.

$4=0$.

[v21] Fala-se muito sobre quais objetivos o Brasil deve procurar atingir nos próximos dez anos. Neste cartão estão alguns objetivos que as pessoas dariam prioridade. Qual deles o(a) Sr(a). acha o mais importante?

[V22] E em segundo lugar? 
Codificação: $\quad 1=$ Alto nível de crescimento econômico.

$2=$ Garantir um forte sistema de defesa militar para 0 país.

$3=$ Aumentar a participação das pessoas nas decisões que são tomadas em seus trabalhos e em suas comunidades.

$4=$ Tentar fazer com que as nossas cidades e 0 interior do

Recodificação: $\quad 1=0$ país fiquem mais bonitos.

$2=0$.

$3=1$.

$4=1$.

0 índice foi construído a partir da somatória das variáveis V17 a V22 e varia de 0 a 6.

\section{Indice de adesão à democracia}

[V82] Questão: Gostaria que o(a) sr.(a) me dissesse qual das três frases seguintes se aproxima mais do que o(a) sr.(a) pensa:

Codificação: $\quad 1=$ A democracia é sempre melhor do que qualquer outra forma de governo.

2 = Em certas situações, é melhor uma ditadura do que um regime democrático.

$3=$ Tanto faz se o governo é uma democracia ou uma ditadura.

Recodificação: $\quad 0=$ A democracia não é sempre melhor do que qualquer outra forma de governo.

1= A democracia é sempre melhor do que qualquer outra forma de governo.

Questão (comum): Vou descrever alguns tipos de sistemas políticos e gostaria de saber o que o(a) $\operatorname{Sr}$ (a) pensa sobre cada um deles como modo de governar o País. Para cada um, diga se é ótimo, bom, ruim ou péssimo? e com eleições.

[V83] Ter um líder forte que não precise se preocupar com deputados e senadores

[V85] Ter um governo militar.

[V86] Ter um sistema político democrático. 


$$
\begin{array}{ll}
\text { Codificação: } & 0=\text { Péssimo. } \\
& 1=\text { Ruim. } \\
& 2=\text { Bom. } \\
& 3=\text { Ótimo. }
\end{array}
$$

Recodificação (V83 e 85): $\quad$ 0= Ótimo.

$$
1=\text { Bom. }
$$$$
2=\text { Ruim. }
$$$$
\text { 3= Péssimo. }
$$

0 índice foi construído a partir da somatória das variáveis V82, V83 e V85 recodificadas e V86 e varia de 0 a 10.

Fatores responsáveis pela pobreza

Questão (comum): Dentre as razões abaixo relacionadas, em que medida o(a) sr.(a) acredita que cada uma delas é responsável pela pobreza no Brasil?

[V26] 0 não cumprimento das funções sociais do Estado.

[V27] Falta de vontade política.

[V28] Falta de consciência social das elites.

[V29] A lógica inevitável do sistema capitalista.

[V30] Monopolização das oportunidades por poucos.

[V31] Concentração de renda.

[V32] Falta de empenho dos pobres.

Codificação: $\quad 1=$ Pouco responsável.

$$
\begin{aligned}
& 2=2 \\
& 3=3 \\
& 4=4 \\
& 5=5 \\
& 6=6 \\
& 7=7 \\
& 8=8 \\
& 9=9 \\
& 10=\text { Muito responsável. }
\end{aligned}
$$

Recodificação: Sem necessidade.

Contribuição das ações/medidas para a redução de desigualdades 
Questão (comum): Em que medida o(a) sr.(a) entende que as seguintes iniciativas podem contribuir com a redução das desigualdades sociais no Brasil?

[V43] Tornar os serviços públicos sociais mais eficientes.

[V47] Ampliar os gastos públicos com programas sociais.

[V50] Apoiar iniciativas de entidades não lucrativas voltadas à função social.

$\begin{array}{ll}\text { Codificação: } & 1=\text { Pequena contribuição. } \\ & 2=2 \\ & 3=3 \\ 4=4 \\ 5=5 \\ 6=6 \\ 7=7 \\ 8=8 \\ 9=9 \\ & 10=\text { Grande contribuição. } \\ & \text { Sem necessidade. }\end{array}$

Percepções sobre políticas públicas

Questão (comum): Gostaríamos que o(a) sr.(a) avaliasse as seguintes políticas de acordo com as seguintes alternativas: viável e desejável, desejável mas não viável, viável mas não desejável ou nem viável nem desejável.

[V52] Educação básica gratuita e universal.

[V53] Programa de construção de casas populares.

[V54] Acesso universal e gratuito aos serviços de saúde.

[V55] Aposentadoria por tempo de serviço.

[V56] Seguro-desemprego para todos os trabalhadores.

[V58] Cotas sociais nas universidades e nos serviços públicos.

[V59] Cotas raciais nas universidades e no serviços públicos.

[V60] Desenvolvimento econômico combinado com proteção ao meio ambiente.

Codificação: $\quad 1$ = Viável e desejável.

$2=$ Desejável mas não viável.

3= Viável mas não desejável.

$4=$ Nem viável nem desejável.

Recodificação: Sem necessidade. 